\title{
Knowledge Based Capital in Digital Age
}

\author{
Bykovskaia G.A.* \\ Voronezh state University of engineering technologies, \\ Voronezh, Russia \\ e-mail: kaf15_vrn@mail.ru
}

\section{Babaeva A.V.}

Voronezh state University of engineering technologies, Voronezh, Russia

e-mail: annabab1@yandex.ru

\author{
Larina L.I \\ Voronezh state University of engineering technologies \\ Voronezh, Russia \\ e-mail: lil-2010@yandex.ru \\ Chernykh W.D. \\ Voronezh state University of engineering technologies, \\ Voronezh, Russia \\ e-mail: vbr2010@bk.ru
}

\begin{abstract}
The paper analyzes the socio-cultural changes that have occurred in the modern world. The trends and issues of digital society are investigated. The authors examine theoretical studies on the problems and prospects of development of world civilization. Having summarized the current views of researchers in various fields of knowledge, the authors have highlighted the "key points" of the modern digital age. The role of netocracy, "network production", and "e-democracy" in modern societies is demonstrated. Special attention is paid to the formation and development of "knowledge based capital". The strong correlation of modern economic models with the development of educational systems is emphasized. The architecture of the educational space in digital age is increasingly perceived not only as a place for the transfer and formation of highly professional knowledge and skills, but as a way of developing creative thinking and promoting the process of building individual trends of development and personal growth, and create a need for constant self-education. Such revolutionary changes in the traditional education system will increase the share of the domestic knowledge based capital.
\end{abstract}

Keywords - digital economy, netocracy, knowledge based capital, knowledge-driven society, human capital investments.

\section{INTRODUCTION}

More than a hundred years ago, M. Weber, in his work "The Protestant Ethics and the Spirit of Capitalism", first published in 1904-1905, emphasized that "the modern economic order ... is now bound to the technical and economic conditions of machine production which today determine the lives of all the individuals" [2]. But mankind turned out to be ultimately "bound" to technical devices only at the end of the twentieth century. The fundamental shift in the process of "linking" a person to a machine begins in 1969. On December 5, 1969 the world enters, without realizing it, into a new era. Such an insignificant event, at first sight, as the link of three computers in California and another one in Utah, led to the birth of the Internet, which marked the beginning of global sociocultural transformations. Information technologies, as the history of their development has shown, differ from all other technologies invented and introduced along the development of human civilization, primarily in that they have a special cultural function. Back in 1985, an American researcher J. Moor emphasized that "the twentieth century is the era of the computer revolution," in which two stages can be distinguished [17]. The first stage is associated with the development and improvement of IT systems, which the majority of countries went through at the end of the 20th century. The second one is the integration of all public institutions in the IT space that is happening right in front of us. The Internet, moving apace around the world, contributed to the birth of a new digital economy, politics and culture. The World Wide Web has formed new principles of human activity. The Internet has been able to transform our world into a kind of a "global village", a global community that exists and develops in cyberspace. In digital civilization, life begins to be perceived as a principle of dissemination of information [1].

For the first time ever, features of the information age have attracted the attention of economists. In 1962, F. McLap's book "Production and distribution of knowledge in the United States" was published in the United States, which is traditionally considered the first one among the studies of the information society.

In 1969, P. Drucker, relying on McLap's research, publishes the work "The Age of Discreteness", in which he examines the formation and development of the "knowledge driven society". P. Drucker in his work suggested that already in the 70s of the twentieth century, "knowledge based capital" formed in the "knowledge driven society" would not only displace all other types of industries, but would make up more than $50 \%$ of the domestic national product of North America.

Further study of the information society is associated with the works of D. Bell. His work "The Coming Postindustrial Society" (1973) became the "Bible" of researchers of information civilization for many years. In this work, D. Bell associated the further development of civilization with the production of knowledge and information, which will displace all other types of production and transform all types of human activity.

The next stage in the study of the processes and problems of information civilization or "network space", "cyberspace", "knowledge driven society", "digital society", etc. is associated with the research of K. Gelbraith, E. Masouda, and 
Yu. Hayashi. Sociological aspects of informational reality are presented in the works of S. Jones, M. Castells, F. Webster.

The development of mass culture and "consumer society" has created a whole trend in humanitarian research. These issues were investigated in the works of B. Barber, Z. Brzezinski, J. Baudrillard, T. Rozsak, R. Rorty, U. Eco, and others.

The second half of the $90 \mathrm{~s}$ of the twentieth century demonstrated a new phase in the development of information reality. The contradictions of this model of development have become more acute, and the idea of the "end of history" appears. Along with pessimistic views, the works of popularizers of the information society M. Dertouzos, K Kelly, M. Minsky, K. Warwick appear.

As we can see, there is a fairly extensive group of studies devoted to various problems of the information society, the formation and development of "knowledge based capital". In our opinion, comprehensive research is still needed, both generalizing and dedicated to the dynamics of individual aspects of the digital society.

\section{RESEARCH METHODOLOGY}

The theoretical and methodological basis of the study is the philosophical-anthropological and historical-cultural principles, as well as a systematic approach.

The study is empirical in nature, since it studies phenomena that need to be more deeply understood, systematized and structured.

The research presented in this paper is based on a synthesis of the listed approaches and develops a philosophical and anthropological direction.

\section{DISCUSSION}

The modern world is called "information-driven", "cyberspace", "digital", the age of "network intelligence", etc. All these terms emphasize an essential feature of modernity computer networks have become the core of social, economic, cultural and other transformations.

The world of dynamic changes has altered people's ideas about time, space, and human beings. In the digital world, many spaces interact with each other, the boundaries of which are easily changed and often invisible. Communication media frees a person from "attachment" to a particular place. Multilayer hyperspace allows "stretching" the time of communication. A person can choose a new role, "hide" behind another appearance. The carnival game, the avatars game allows building new value-normative systems; an idea appears that in digital civilization, "Homo sapiens" is being replaced by "a man of many faces". Multi-faces, which do not have a fundamental relationship with gender, age, education, and other markers of socio-cultural identity, everyone decides on his own what roles and when to use in communication. [14].

The digital world, actively intervening in all spheres of human life, leads to deeper transformations of a person. Plunging into the numerous streams of communication, a person uses more and more separate "fragments" of his thinking, which creates "fragmentation" of the worldview, consciousness, and strengthens the problems of identity.

In such conditions, the traditional value-normative system has ceased to meet the requirements of modernity. There is an urgent need to create a new axiological system in which the value of knowledge and information comes first. Information has become the basis of social development. Within a generation, information technology in developed countries has almost replaced the economic models that existed in the industrial world.

Information and primary access to it have become important strategic resource of the state. People have been devided into netocracy, i.e. those who own information can get it "first hand", and "new poor", those who do not have access to information or receive "secondary" information from netocracy. The term "electronic inequality" has become one of the main terms used in assessing global development. "Edemocracy", "e-government" has become the realities of our time. Along with these concepts, the concept of "engineers of the worlds" (P. Levy) appeared. "Engineers of the worlds" mean the creators and builders of communication networks, game developers, and designers of the various principles of information accumulation.

Along with a variety of benefits, the digital age has also created new challenges. The world is increasingly filled with artificially created media events. Human desires are more and more falling into the system of artificial formation. As the Swedish researcher A. Bard noted: "The system prompts desires through advertising and then allocates solid resources to maintain consumption at a level that suits netocrats" [1]

In the digital age, oddly enough, it is not the consumer who comes out on top, but the producer of information and information technologies. Therefore, knowledge becomes a particularly valuable product. Hence the growing attention to the production of "knowledge based capital" occurs. The increase in its share in the national gross product is directly linked to the conditions for further successful development of the society. Thus, in the United States more than $60 \%$ of national income is provided by the growth of knowledge, i.e. "knowledge based capital".

The report on human development in the Russian Federation for 2018, prepared by the analytical center under the Government of the Russian Federation, noted that the United States is the leader in terms of gross outlay on scientific research. This report also highlighted that the most actively developing European and Asian countries, such as the United Kingdom, Germany and South Korea, were able to achieve a level of $40 \%$ or higher of gross domestic product due to science-driven and high-tech industries [4]. Intellectual and innovative revolutions are accompanied by a creative revolution. Creativity becomes the most important quality of a modern specialist and the main management functions. This is not accidental, because the dynamism of the digital society has led to a situation where no one can predict with certainty which special knowledge or skills will be most in demand in the nearest future. Creative abilities become a necessary requirement for survival in such conditions. 
In this regard, the requirements for the education system as the main mechanism for the production of knowledge based capital have changed. "The world is changing so quickly, and education systems are so stagnant and inert, as if, caught in a time trap, they continue to serve a past era that has long since ended." [5].

In our country, problems of education have been discussed and continue to be talked about at various levels. Education problems were also included in the "Strategy for the Development of the Information Society in Russia", adopted in 2007. This document emphasized that the Russian education system does not provide high-quality reproduction of specialists needed in the digital economy. Further integration into the global world economy is possible only with changes in the education system [11].

However these are not only the problems of our country. The entire world community is in search of a new architecture of the pedagogical space and the selection of the most appropriate educational technologies that could not only train highly qualified specialists, but also lay the foundation for the creative development of the individual. The problems of modernization of education systems have become an important strategic task of world development. It is no coincidence that in 2016 the UNESCO World Monitoring Report on Education emphasized that without the development of education, there can be no future for humans and humanity [11]. In addition, the report noted that not only changes in the education system are required, but also a fundamental change in people's attitude to education, and the formation of a stable idea that a person's well-being and further successful development depends only on education. The UNESCO report emphasized that the digitalization of society required "highly skilled employees with creative thinking and the ability to solve various problems, but also supplanted middle-skilled workers, whose rather monotonous and procedural tasks can be easily reproduced using computer equipment and programs and transferred for the borders of the country" [9].

Therefore, the tasks were set to transform the traditional education system, to make it more flexible and mobile. As a result, the idea is formed that the educational system needs radical restructuring, revolutionary changes. In 2003, the book by G. Dryden, J. Voss "A Revolution in Learning" was published in which the authors pay special attention to the transformations that must be carried out to create a new educational space. They emphasized that "the real revolution in learning is not only about changing the school system. It consists in learning how to learn, in learning how to think, in learning new methods that we can use to solve any problem that arises before us, at any age. The digital revolution is becoming a catalyst for the process of a complete redefining of teaching and teaching methods" [5].

An active search for new architectural solutions in the education system was associated with an increase in the share of knowledge based capital in the economies of different countries. The search for new models and technologies is ongoing, as the information / digital era poses new challenges to society.
On the one hand, it is easy to obtain knowledge in the digital world. On the other hand, it is necessary to have critical thinking, the ability to quickly process the information received, highlighting the most significant and "cutting off" outdated information. "This all-destructive information flow is not structured and not sorted: if we want it to become a source of knowledge, and not a misconception, it must be sifted, sorted and comprehended in accordance with modern ideas about the world" [1]. The same views are expressed by a Spanish sociologist and researcher of the digital world, M. Castells. He notes that in the modern world, there are acute questions of "what and how to teach". Moreover, these issues are not only for those who teach children and young people, but also for managers of firms and industrial enterprises. In many ways, these issues are related not only to the sharp increase in knowledge, but also to the dynamism of the digital world. M. Castells emphasizes: "most of the special information, as a rule, becomes outdated within a few years, because we live in an economy that changes with the speed of the Internet" [7].

Such unprecedented dynamism has created the idea that the modern world instability, uncertainty and ambiguity reign. The world is more and more often called the world of UCA (an abbreviation for English words: U stands for uncertainty, C stands for complexity and A stands for ambiguity). In such conditions, pedagogical models of advanced and continuing education come to the first place in the training system. The concept of "continuous learning" was first used in 1929. It was this year that the book "Continuous learning: an essay on the spread and significance of the Adult education movement "was published by an English scientist Yoxley.

In the late 60 s and early 70 s of the twentieth century, the concept of "continuous education" began to be actively used in UNESCO reports and programs.

A new round of attention to life-long learning falls at the end of the twentieth century. At this time, the idea is confirmed that it is the advanced development of education that allows society to "survive" in modern conditions, and not be "on the margins" of the civilizational process.

In March 2000, the European summit in Lisbon adopted the "Lifelong learning" project, or Memorandum of continuing education, based on the ideas of continuous education. The Memorandum highlighted the point that basic knowledge is necessary for a modern man. These included digital literacy, knowledge of foreign languages, technological culture, entrepreneurship, and social skills. In addition, it was emphasized that the successful development of a knowledge driven economy is possible only with the full use of the human factor. Therefore, it is necessary to increase investment in human resources and raise the importance of human beings in the information civilization.

In 2001, the idea of continuous education was included in the Bologna process.

Recently, a different conceptual approach has been formed, which has found expression in the concept of "lifewide education" (lifewide learning), in which the main emphasis is placed not only on the constant learning process, 
but on the variety of educational forms (such as formal, informal, informational). The idea of "life-wide" education is based on the idea that the whole world is a school for a person, where he can and should study.

In January 2019, another report on the results of monitoring the educational process was presented in London "Trends shaping education 2019". In this report, a special place had a section devoted to the formation of future thinking, based on foresight methodologies. It was noted that without the development of perspective thinking, a modern specialist is doomed to defeat, because he is not able to calculate the risk, refrain from dangerous decisions, and consistently implement the chosen strategy. Foresight ideas and methods are actively used in the framework of modern management. In 2012, one of the most popular western management researchers, Henry Mintzberg, noted: "first-class performance of thinking is to discover new strategies that can rewrite the rules of the competitive game and foresee a possible future that is radically different from the present" [10].

As noted above, the complexity, ambiguity, and active development of the modern world lead to dramatic changes in perception of professional activities over the past 10-15 years. Over this period of time, the forms of organization of the labor process have changed. The most successful model was the "web", which is increasingly called the "network" after the example of the Internet device. "Network marketing", "network production", "network advertising" have become familiar in our world. There is a perception that the "network structure" is the fundamental material from which new organizations are created and will be created, since "networks" use innovative technologies. The global economy is the most striking example of a "network economy". [9].

The network structure required multi-pronged employees capable of dynamic development, advanced training and personal growth. No wonder that such concepts as "information management", "self-management", and "emotional intelligence" have appeared, which reflect modern requirements for the system of education and professional training of a person. In the context of increasing importance of virtual production, personal competence, creativity, mobility, clear goals and motives matter more than job titles or job descriptions. The place of study and work more and more often represents a single space: "work-based learning and the experiential learning" [8]. The combination of training and work processes was the basis of a new form of management and is considered, at the moment, the most successful business model. In the modern digital era, "success is achieved by organizations that are able to generate knowledge and effectively process information; adapt to the changing geometry of the global economy; be flexible enough to change their means as quickly as goals change under the influence of rapid cultural, technological and institutional changes; introduce innovations, since innovation has become a key weapon of competition " [8].

\section{RECOMMENDATION}

The architecture of the educational space in digital age is increasingly perceived not only as a place for the transfer and formation of highly professional knowledge and skills, but as a way of developing creative thinking. "Gifted people are the main factor of production in the field of electronic business" [7]

Technologies that currently allow approaching the requirements of economy and increasing the share of knowledge based capital in the country's GDP should take into consideration all the changes that have happened to man himself. That is why the following strategies come to the fore in the education system:

1. Gamification in the education system. In modern research, the term "generation of kidults and iPads" is increasingly appearing meaning that the game is the norm of life for people. The game becomes the dominant form of education and social life. Therefore, in the learning process, chats in messengers, Skype - conferences, closed groups in social networks are used increasingly.

Smart training. "A distinctive feature of smart technologies is their ability to instantly respond to changes in the environment. The main task of smart-training is to create conditions for obtaining new efficiency in the educational process [3].

This method gives faith to the development of the adaptive capabilities of the individual. Smart-training, first of all, should form the ability to set consistent goals, find and critically evaluate additional information.

3. Video content. This model is used primarily in the Russian education system. In the global community, video content is used as part of "flipped learning". This model has been used since 2007. Its authors are American chemistry teachers Jonathan Bergman and Aaron Sams. When developing this training model, J. Bergman and A. Sams put in the first place an individual approach to the learning process, which allows building individual trends. J. Bergman noted: "the traditional education system wants all children to move through the pages of the textbook simultaneously, but this is impossible. In the "flipped model," those who understand everything simply move on to the next topic and those who do not move spend a little more time understanding" [16]. The essence of this model is that students at home watch short video lectures, and in classrooms all the time is devoted to discussion and / or practical application of the knowledge gained.

4. Micro-training, by which we mean splitting information into small pieces. This way the information will be memorized more deeply, furthermore it is easier to work with a small amount of information. And if we take into account that many courses are held today from a mobile or tablet, then small videos and texts on 3-5 mobile screens are just the amounts that will not cause problems for users.

5. Personalized training. An option that allows including people with different abilities and capabilities in the training system and help build an individual trend. Personal training 
proposes not only a flexible schedule for students, but also the possibility to choose the sequence of topics and subjects to study.

6. Peer-to-peer (peer-to-peer learning). This model focuses on peer education. The peer-to-peer model has worked well both in classical training systems (school, university), as well as in continuing education systems, group training on enterprises. Researchers note that this model allows not only successful learning and sharing experience, which leads to an increase of knowledge in the organization, but also attracting "external knowledge". In an economic system where innovation is critical, the organization's ability to increase sources of knowledge by scooping them of all forms of knowledge, becomes the cornerstone of an innovative firm" [8].

This model can also be used in the classical space of knowledge transfer - in the system of secondary and higher education. It has long been confirmed that material is assimilated the best, if a person is trying to transfer it to others [15].

Very often, the reason for unsatisfactory results in the process of increasing knowledge based capital or its accumulation is not a lack of knowledge, but a neglect of knowledge that does not concern the direct competence of the specialist. Therefore, people are increasingly talking about the need to train fewer specialists who have only specialized knowledge and skills. In addition to direct professional knowledge, the modern digital world requires a person to have an extensive background in the fields of management, psychology, ethics, and conflict management. The changes that have taken place in the professional community have contributed to the "blurring" of clear boundaries between humanitarian and technical issues. Nowadays, a representative of any profession is faced with challenges, dilemmas and issues that a few years ago were referred to the field of humanities.

\section{CONCLUSION}

The development of knowledge based capital is directly related to the development of new competitive strategies, a creative approach to any task, and the replacement of the "man-tech" system by the "man-man" system [12]. It is no mere chance that knowledge based capital has become the basis for the development of the modern world.
The modern education system should not only form critical thinking, but also promote the process of building individual trends of development and personal growth, and create a need for constant self-education. Such revolutionary changes in the traditional education system will increase the share of the domestic knowledge based capital.

\section{References}

[1] M. Weber, The protestant ethics and the spirit, In: M. Weber, Selected works: TRANS. Comp. Moscow: Progress, 1990, 123 p.

[2] J. Moor, Metaphilosophy. Oxford, 1985, vol. 16, no. 4, 266 p.

[3] A. Bard, J. Soderqvist, Theocracy. The new ruling elite and life after capitalism, Transl. from Swedish. St. Petersburg: Stockholm school of Econ. in Saint Petersburg, 2004, pp. 39-41.

[4] J. Suler, People turn into electronics. Basic psychological characteristics of cyberspace, Per. Elena Vovk. Retrieved from: https://hrportal.ru/article/dzhon-suler-lyudi-prevrashchayutsya-v-elektronikovosnovnye-psihologicheskie-harakteristiki

[5] Report on human development in the Russian Federation for 2018 Under the General editorship S.N. Bobylev, L.M. Grigoriev. Moscow: Analytical center under the Government of the Russian Federation, 2018.

[6] G. Dryden, A. Voss, Revolution in learning. Moscow: Parvine, 2003, pp. 107, 111-115

[7] Education for people and the planet: building a sustainable future for all Retrieved from: https://unesdoc.unesco.org/ark:/48223/pf0000245752_rus

[8] N. Kudryavtseva, Y. Pakhomova, Y. Duvanova, "The concept of management development management enterprise", Proc. of the Voronezh State Univer. of Engineer. Technol., vol. 81, no. 1, pp. 429-433, 2019. Retrieved from: https://doi.org/10.20914/2310-1202-2019-1-429-433

[9] M. Castells, The Internet Galaxy. Retrieved from: https://libking.ru/books/comp-/comp-www/436586-manuel-kastelsgalaktika-internet.html

[10] H. Mintzberg, School of strategies. Strategy Safari: a guided tour through the wilds of strategic management. (collector). Retrieved from: https://www.livelib.ru/author/227777/top-genri-mintsberg

[11] M. Castells, The Information age: economy, society and culture. Retrieved from: https://www.gumer.info/bibliotek_Buks/Polit/kastel/03.php

[12] M. Castells, The Information age: economy, society and culture. Retrieved from: https://www.gumer.info/bibliotek_Buks/Polit/kastel/03.php

[13] N. Dneprovskaya, E. Yankovskaya, I. Shevtsova, "Conceptual foundations of smart education", Open education-2015, no. 6, pp. 43-51.

[14] What is a "Flipped class"? Retrieved from: https://mel.fm/shkola/ 928534-flipped_classroom

[15] Trends in modern education. Retrieved from: https://edmarket.ru/blog/ top-trends-of-e-learning

[16] Y. Salikov, I. Logunova, I. Kablashova, "Trends in human resource management in the digital economy", Proc. of the Voronezh State Univer. of Engineer. Technol., vol. 81, no. 2, pp. 393-399, 2019. Retrieved from: https://doi.org/10.20914/2310-1202-2019-2-393-399 